\title{
BMJ Open Perceptions and experiences of the public regarding the COVID-19 pandemic in Nepal: a qualitative study using phenomenological analysis
}

\author{
Navin Bhatt (D) , ${ }^{1}$ Bandana Bhatt (D) , ${ }^{2}$ Soniya Gurung, ${ }^{3}$ Suresh Dahal, ${ }^{4}$ \\ Amrit Raj Jaishi, ${ }^{4}$ Bandana Neupane, ${ }^{5}$ Shyam Sundar Budhathoki ${ }^{6}{ }^{6}$
}

To cite: Bhatt N, Bhatt B, Gurung S, et al. Perceptions and experiences of the public regarding the COVID-19 pandemic in Nepal: a qualitative study using phenomenological analysis. BMJ Open 2020;10:e043312. doi:10.1136/ bmjopen-2020-043312

\section{- Prepublication history and} additional material for this paper are available online. To view these files, please visit the journal online (http://dx.doi org/10.1136/bmjopen-2020043312).

Received 31 July 2020 Revised 09 November 2020 Accepted 30 November 2020

Check for updates

(C) Author(s) (or their employer(s)) 2020. Re-use permitted under CC BY-NC. No commercial re-use. See rights and permissions. Published by BMJ.

For numbered affiliations see end of article.

Correspondence to

Dr Navin Bhatt;

n.navin.bhatt@gmail.com

\section{ABSTRACT}

Objectives Perceptions of people regarding COVID-19 influences their health behaviour in terms of seeking public health services. This helps the government in planning appropriate public health strategies. Therefore, this study intends to explore the perceptions of people towards COVID-19 and their experiences during the pandemic in Nepal.

Design, setting and participants This qualitative study was conducted among the public in Kathmandu, Kanchanpur, Bajura and Jhapa districts of Nepal. Eight focus group discussions and 40 in-depth interviews were conducted by using a maximum variation sampling method.

Results The findings were organised into the following themes: General understanding of COVID-19, Disease prevention, Source of information and misconceptions, Expectation and challenges; and Personal and societal consequences of COVID-19, social distancing and lockdown. There was a good general understanding among respondents about COVID-19, personal preventive measures and population-level strategies. They responded that the use of masks, sanitisers, handwashing and proper lockdown would help to prevent the disease. The respondents acknowledged the vital role of media in increasing awareness. Participants also expressed concerns over the misleading news spread by some media. The lack of social interaction, isolation and loss of income were raised as pertinent issues by the participants as potentially leading to psychological consequences. Health workers and public both raised concerns over inadequate Personal Protective Equipment, under-prepared health system, unorganised public quarantine centres, and public violation of lockdown

Conclusions This study reports participants' views on disease prevention measures such as maintaining personal hygiene, adhering to physical distancing, and using personal protective equipments. Additionally, it illuminates the confusion among public due to conflicting public health messages from different sources of information which was deemed as misleading by the participants. This research sheds light on people's perspectives and experiences that can inform population-targeted policies in the future.
Strengths and limitations of this study

- Representation of participants from diverse backgrounds.

- A large number of participants interviewed in a short period of time abiding preventive measures and safety guidelines.

- Use of the phenomenological approach has enriched the evidence generated from the lived experiences of people.

- Children and the elderly population excluded from the study due to the possibility of increased risk of COVID-19.

- Hesitancy of participants to participate in the focus group discussions due to different stages of lockdown and disease outbreak in different parts of the country.

\section{INTRODUCTION}

The COVID-19 is a newly discovered infectious disease, first seen in December 2019 at Wuhan city of Hubei province, Central China. A rapid spread with a high transmission rate and substantial deaths have been observed worldwide affecting 216 countries, areas or territories already. ${ }^{12}$ The World Health Organization (WHO) declared the COVID-19 outbreak as a global pandemic on 11 March 2020. ${ }^{3}$ In Nepal, the first case was confirmed on 23rd of January $2020,{ }^{4}$ in a person who had returned from Wuhan. ${ }^{5}$ It was also the first recorded case of COVID-19 in South Asia. ${ }^{6}$ The total cases in Nepal reached 188883 as of 6 November 2020, with 1070 mortalities. ${ }^{4}$

Countries around the world are implementing different measures, from local quarantines to travel restrictions, to prevent wide spread of the virus. ${ }^{7}$ Nepal is a risk zone for COVID-19 due to its weak health system and porous borders with India. ${ }^{8}$ The government of Nepal adopted various preparedness measures viz.: establishing and strengthening 
the health desk at International Airport, Nepal-China and Nepal-India borders; designating COVID-19 hospitals-to prevent and control infection and provide critical care where available; procuring and stockpiling Personal Protective Equipment (PPE), laboratory items and ventilators; and allocating spaces for quarantine purposes throughout the country. Moreover, the risk communication protocol was developed, prevention and protection messages were disseminated in local languages, and case investigation and contact tracing were carried out. The surveillance systems, screening at point of entries, and community level screening and testing were also strengthened, and the Rapid Response Team was mobilised. ${ }^{9}$ On 20 March 2020, the government of Nepal enforced a complete lockdown of the country that included the suspension of international and domestic flights, restrictions on movement and mass gathering, and closures of the schools and colleges, businesses and services apart from those considered essential. People were urged to stay at home maintaining social distance. ${ }^{10}$

The unintended effects among people at all levels are many, ranging from anxiety/stress to reduced freedom on daily living, and from fear of the unknown to loss of income sources. ${ }^{11}$ It has been reported that the strict and prolonged lockdown has various effects such as effects on maternity services and rise in maternal deaths, effects on mental health and rise in suicide cases, effects on children and adolescents, rise in domestic violence, impact on routine health services like child health and immunisation, impacts on logistics and supply management, and impacts on farming. ${ }^{12}$ A study conducted in Nepal showed that $41.9 \%$ of health workers had symptoms of anxiety, $37.5 \%$ had depressive symptoms, $33.9 \%$ had symptoms of insomnia and more than half of the health workers faced stigma. $^{13}$

A study in India reported that the knowledge and practice towards COVID-19 pandemic among people is good but still there was a gap in right perception. ${ }^{14}$ Similarly, in the USA and the UK, people had important misconceptions about COVID-19 whereas, in Nepal, a study reported that the overall knowledge of COVID-19 was high and the majority of people had a positive perception towards universal safety measures. ${ }^{15}$

The future trajectory of the COVID-19 pandemic largely depends on the behaviour of people. ${ }^{16}$ With increasing number of researches conducted on COVID19, some evidence have been generated regarding the transmission of COVID-19, risk factors, preventive methods and health-seeking behaviour of people. ${ }^{14-17}$ However, there is still a dearth of relevant populationlevel research in the context of Nepal, that addresses people's real experiences of living in the pandemic situation. ${ }^{18}$ Understanding the perceptions that people have about the disease, hearing about people's experiences during this pandemic and using this evidence to inform policy could help the country design preparedness plans and preventive strategies for the future. Therefore, this study aims to explore the perceptions that people have towards COVID-19 and their experiences about the social distancing measures applied by the government during the COVID-19 pandemic in Nepal.

\section{METHODS}

\section{Study design}

The phenomenological approach of qualitative research design was used due to lack of previous studies on the topic for Nepal. The use of phenomenological approach helped explore and understand people's own perspectives and description of the events from their lived experiences. ${ }^{19}$ This approach was also instrumental in identifying key topic areas and interview guide for data collection based on the preliminary interactions with the research participants. This study was conducted from March to June 2020.

\section{Researcher characteristics and reflexivity}

The interviewer team comprised of experts from different health fields that included two public health researchers, two medical doctors and one postgraduate resident who had the experience of conducting the qualitative research design. Before the data collection, an online video meeting was conducted for all the members of the research team on interviewing, facilitating, recording, note-taking and transcribing. The research team and the research participants were not familiar with each other, personally and professionally.

\section{Study sites}

Based on proximity to greater risk factors of an outbreak in Nepal and to include diverse population from different geographical regions of Nepal having heterogeneity of health facilities, culture, tradition, people's behaviour and geographical access to the effective health services, Kathmandu, Kanchanpur, Bajura and Jhapa districts were selected purposively. The population profile of the districts is described in online supplemental file 1 . The location of the study sites in different districts is listed in table 1 . The municipalities in the district were conveniently selected and wards were selected randomly.

\section{Study population and sampling technique}

After the random selection of the wards, as per the Government of Nepal's regulation to prohibit large gatherings of people at a place as a preventive measure for the COVID-19 outbreak, each focus group discussion (FGD) consisted of six people who were placed at a 1-metre distance from one another in open space. Additionally, face masks were provided to the participants, and alcoholbased hand sanitisers were made available to each of the focus groups to further reduce the risk of exposure.

The participants that represented diverse backgrounds in terms of gender, profession, education, geography and social status were selected using a maximum variation sampling method. We announced participant recruitment for the study through local social networks and 
Table 1 Location of study sites

\begin{tabular}{lllll}
\hline Province & Districts & Municipality & Ward number & Local address \\
\hline Bagmati Pradesh & Kathmandu & Kathmandu Metropolitan City & 7 & Chabahil \\
Sudurpashchim Pradesh & Kanchanpur & Bhimdatt Municipality & 2 & Mahuliya/Ultakham \\
Sudurpashchim Pradesh & Bajura & Budhiganga Municipality & 5 & Thuma \\
Province No. 1 & Jhapa & Mechinagar Municipality & 11 & Dhaijan \\
\hline
\end{tabular}

invited potential participants aged 18-60 years to participate in the FGD. For the FGD, a maximum of one participant was included from a house on a voluntary basis. For the in-depth interview (IDI), individuals who were at the forefront in the community such as the healthcare workers (doctors, nurses, laboratory workers) of the local hospital, security personnel (Nepal Police, Nepal Army, Armed Police Force), media personnel, school teachers, local leaders, female activists, human rights advocates, local public health experts, students, shopkeepers, drivers and daily wage labourers were selected for the participation. These people are at greater risk of transmission of COVID-19 and most of them are directly involved in the management of the situation. Data were collected in a community setting either at the household or at a place preferred by the research participants.

A further collection of data was ceased after the saturation of data. Data were considered to have reached saturation when the response from participants had started repeating or no new themes emerged.

\section{Criteria for sample selection}

Among the respondents to our call, we enrolled all people who were willing to participate in the study and provide written informed consent for the study. People who were less than 18 years or more than 60 years, pregnant, or those suffering from infectious disease or having underlying conditions were excluded from the study.

\section{Data collection methods and technique}

FGDs were conducted using a topic guide, involving a moderator responsible for guiding the discussion and a note-taker responsible for taking notes, noting down non-verbal responses and ensuring the tape-recording. A total of eight FGDs were conducted, two in each district. Each FGD lasted for 60-90 min on average. The IDI was conducted by a single researcher using the interview schedule comprising of open questions on COVID-19, and personal experiences of living during the pandemic. After obtaining informed consent, the interview was conducted at a location convenient for the respondent. A total of 40 IDIs were conducted, with each IDI lasting for 30-45 min on average.

The discussions and interviews in Kanchanpur and Bajura districts were conducted in the local (Doteli/ Pahadi) language although respondents tended to mix Doteli and Nepali languages during the interviews; whereas, in other study districts, Nepali language was used and were tape-recorded. The data were collected for a duration of 2 weeks. After completion of the data collection, the tape-recorded discussions and interviews were transcribed directly into the English language by an expert language translator.

The validation of the tool was ensured by the index of item-objective congruence and consultation with the experts. A pretesting, consisting of one FGD and four IDIs, was conducted prior to the study, and the changes required were incorporated. The trustworthiness of the data was met through triangulation of different aspects of data collection: (1) among different respondents and (2) using different methods of data collection such as IDIs and FGDs.

\section{Data processing and analysis}

The collected data from the focus groups and interviews were transcribed verbatim. A member of the research team, conversant in Doteli, Nepali and English language, cross-checked the transcripts for accuracy and language translation consistency.

Colaizzi's phenomenological analysis method was used to analyse the transcript. The analysis included steps such as familiarisation, identifying significant statements, formulating meanings, clustering themes, developing an exhaustive description, producing the fundamental structure and seeking verification of the fundamental structure. $^{20}$ Two researchers were involved in independently reviewing the data and formulating the themes after summarising and extracting the meaningful contents, bracketing the presuppositions of the researchers.

\section{Patient and public involvement}

Patients and/or the public were not involved in the design, or conduct, or reporting, or dissemination plans of this study.

\section{RESULTS}

A total of eight FGDs were conducted in four districts: Kathmandu Metropolitan City-7, Kathmandu; Bhimdatt Municipality-2, Kanchanpur; Budhiganga-5, Bajura and Mechinagar-11, Jhapa, comprising of 24 men and 24 women above 18 years of age. Similarly, 40 IDIs were also conducted among people from these districts. The baseline characteristics of the participants are given in table 2 .

The responses from the IDIs and FGDs were classified into five broad themes. Within each broad theme were several subthemes. The themes and subthemes are 
Table 2 Sociodemographic characteristics of the participants

\begin{tabular}{|c|c|c|}
\hline & $\begin{array}{l}\text { FGD } \\
\text { participants }\end{array}$ & IDI participant \\
\hline Variable & Number (\%) & Number (\%) \\
\hline \multicolumn{3}{|l|}{ Age group } \\
\hline $18-30$ & $12(25)$ & $12(30)$ \\
\hline $31-40$ & $18(37.5)$ & $14(35)$ \\
\hline $41-50$ & $10(20.83)$ & $8(20)$ \\
\hline $51-60$ & $8(16.67)$ & $6(15)$ \\
\hline \multicolumn{3}{|l|}{ Sex } \\
\hline Female & $24(50)$ & $18(45)$ \\
\hline Male & $24(50)$ & $22(55)$ \\
\hline \multicolumn{3}{|l|}{ Religion } \\
\hline Hindu & $30(62.5)$ & $24(60)$ \\
\hline Buddhist & $8(16.67)$ & $8(20)$ \\
\hline Muslim & 4 (8.33) & $4(10)$ \\
\hline Others & $6(12.5)$ & $4(10)$ \\
\hline \multicolumn{3}{|l|}{ Marital status } \\
\hline Single & $18(37.5)$ & $15(37.5)$ \\
\hline Married & $30(62.5)$ & $25(62.5)$ \\
\hline \multicolumn{3}{|l|}{ Ethnicity } \\
\hline Brahmin & $14(29.17)$ & $12(30)$ \\
\hline Chhetri & $12(25)$ & $12(30)$ \\
\hline Indigenous & $12(25)$ & $9(22.5)$ \\
\hline Others & $10(20.83)$ & $7(17.5)$ \\
\hline \multicolumn{3}{|c|}{ Highest level of education } \\
\hline Did not go to school & $12(25)$ & $5(12.5)$ \\
\hline Grade 10 or below & $9(18.75)$ & $8(20)$ \\
\hline Grade 12 & $7(14.58)$ & $8(20)$ \\
\hline Bachelor & $12(25)$ & $14(35)$ \\
\hline Masters and above & $8(16.67)$ & $5(12.5)$ \\
\hline \multicolumn{3}{|l|}{ Respondent type } \\
\hline Teachers & $3(6.25)$ & $4(10)$ \\
\hline Students & $5(10.41)$ & $4(10)$ \\
\hline Security personnel & $5(10.41)$ & $4(10)$ \\
\hline Head of household & $5(10.41)$ & $4(10)$ \\
\hline Leaders & $6(12.5)$ & $8(20)$ \\
\hline Health workers & $7(14.58)$ & $8(20)$ \\
\hline Homemaker & $7(14.58)$ & $2(5)$ \\
\hline Others & $10(20.83)$ & $6(15)$ \\
\hline \multicolumn{3}{|l|}{ Resource setting } \\
\hline Rural & $24(50)$ & $20(50)$ \\
\hline Urban & $24(50)$ & $20(50)$ \\
\hline \multicolumn{3}{|l|}{ Geographical location } \\
\hline Himalayan region & $12(25)$ & $10(25)$ \\
\hline Hilly region & $12(25)$ & $10(25)$ \\
\hline Terai region & $24(50)$ & $20(50)$ \\
\hline
\end{tabular}

FGD, focus group discussion; IDI, in-depth interview.
Table 3 Participants' perceptions and experiences during the COVID-19 pandemic

\begin{tabular}{|c|c|}
\hline Theme & Subthemes \\
\hline $\begin{array}{l}\text { General understanding of } \\
\text { COVID-19 }\end{array}$ & $\begin{array}{l}\text { Origin of the disease } \\
\text { Cause of the disease } \\
\text { Mode of transmission } \\
\text { Threats and risk groups }\end{array}$ \\
\hline Prevention of disease & $\begin{array}{l}\text { Information regarding } \\
\text { prevention } \\
\text { Eating habits } \\
\text { Sanitation } \\
\text { Mask and its use } \\
\text { Personal Protective } \\
\text { Equipment (PPE) } \\
\text { Lockdown } \\
\text { Awareness programme }\end{array}$ \\
\hline $\begin{array}{l}\text { Source of information and } \\
\text { misconceptions }\end{array}$ & $\begin{array}{l}\text { Role of media } \\
\text { Credibility of news } \\
\text { Rumours and fallacies }\end{array}$ \\
\hline Expectation and challenges & $\begin{array}{l}\text { Inadequate PPE } \\
\text { Health system management } \\
\text { Violation of lockdown } \\
\text { Demand of people } \\
\text { Quarantine }\end{array}$ \\
\hline $\begin{array}{l}\text { Personal and societal } \\
\text { consequences of COVID-19, } \\
\text { social distancing and } \\
\text { lockdown }\end{array}$ & $\begin{array}{l}\text { Social discrimination and } \\
\text { stigma } \\
\text { Lack of social interaction } \\
\text { Economic loss } \\
\text { Change in lifestyle } \\
\text { Psychological impact }\end{array}$ \\
\hline
\end{tabular}

summarised in table 3 . All verbatim quotes by the respondents can be found in online supplemental file 2 .

\section{Theme 1: general understanding of COVID-19}

Participants mentioned China as the origin of COVID-19. A few expressed the possibility of the COVID-19 being a bioweapon made by powerful countries. When asked about the cause of the disease, the participants believed it to be caused by a virus that spreads through droplets during sneezing and coughing.

...we have been listening about this for about 1 month, so I think it can be transmitted through droplets from mouth and nose during coughing and sneezing. Also touching infected area can transmit the disease. -FF2

Participants agreed that people with low immunity, children, old people and the diseased (asthma, heart disease, liver disease and kidney disease) are more at risk.

\section{Theme 2: prevention of disease}

Participants reported using masks, washing hands or using sanitiser, and maintaining social distance will help in preventing the disease. Similarly, participants also reported that maintaining at least 1-metre distance during the conversation with people was necessary. Some 
said that bathing after returning from the market and changing clothes regularly could prevent transmission.

One thing I am still not sure about the mask, some say surgical masks, some say N95, and some say a mask cannot stop the infection, it's worthless. [laughs...] But I am still using my old mask when I go out. I believe a mask can prevent its (COVID--19) transmission to a significant level. -FM5

Participants believed that the government is trying its best to prevent transmission, but the efforts are not adequate. They opined that the lockdown and border closure were some of the praiseworthy steps of the government to prevent the spread of the disease. It was suggested that enforcing strict lockdown, blocking of borders and social distancing were the most appropriate measures to limit the transmission of this disease. Lockdown would restrict people from moving and carrying the disease to different areas. However, the need for alternatives to lockdown was also suggested as it has created much havoc in the country and would heavily degrade the economy.

The participants thought that still many people especially in the village were not aware of the disease but were frightened. So, they suggested increasing awareness programmes. They also requested media to play a positive role in providing informative programmes rather than reporting only the rising cases and deaths of the people.

\section{Theme 3: source of information and misconceptions}

Participants had heard about the disease from television, radio, newspapers and social media. They were thankful to different media for reporting news from all around the world that helped them to get information about the COVID-19, its transmission, prevention, and day-to-day situation in and around the country.

Participants stated that they didn't completely believe all the information portrayed by media; especially social media was deemed as unreliable as it contained many rumours regarding the COVID-19 cases in Nepal.

No...it's not always true. Some of the negative news spread by media makes people anxious and terrified rather than making them aware. I am very much terrified by the scenes of dead bodies shown by the news. -FF9

\section{Rumours and fallacies}

There were varied perceptions regarding COVID-19 about its origin and its survival. Participants blamed different non-vegetarian food items to be the source of infection. They thought that consuming meat and eggs can cause this disease and suggested people to avoid raw consumption. Moreover, the pervasive notion that virus' survival decreases in hot temperatures was agreed upon by the participants. It was also believed by them that Nepalese people are immune to the virus and would not be affected easily. In addition, they supported the idea of roles of turmeric, onion, tea and alcohol in preventing the disease.

\section{Theme 4: expectations and challenges}

Participants contended the effectiveness of interventions by the government, pointing out that tracing and testing were not being adequately performed. Health workers stated that adequate provision of PPE was not done, which should be the first priority of the government.

Health workers also admitted to harboring palpable fear due to inadequate PPE which also affected their readiness to treat patients as they felt extremely unsafe in doing so. Challenges were further augmented with a sudden shortage of masks and other PPE, and with the revelation of patient's tendency to lie about their travel history fearing doctors may not treat them, as reported by participating health workers. This was considered to pose an increased risk of transmission.

Well, we are always ready to serve patients. But, we have not been provided with adequate protective measures. This would indeed be more dangerous as a single health worker can transmit the disease to hundreds of people at a time. -IF12

Participants made various suggestions to effectively takle COVID-19 disease such as: conducting mass screening, contact tracing and testing, providing sufficient ventilators to hospitals in different parts of Nepal, and effective border seal. Furthermore, they questioned the government's functionality, and condemned the misuse of N95 masks and PPE by some government officials and nonexposed non-frontline staff.

It's disastrous that the healthcare workers and other frontline personnel are not getting adequate PPE to wear. They have been using the same surgical mask for many days; haven't got any other protective equipment. But the government officials and the ministers have been using N95 mask even at home. -FM7

\section{Demand of people}

Participants indicated that public had put many expectations on political parties, health workers, and security forces, some of which were genuine concerns, but which, they argued, were not addressed by the government. However, the participating political leaders argued that most of the demands had been fulfilled but some of the ambitious demands were not important at the moment.

Furthermore, participants lamented about the problems they were facing and requested the government and the leaders to fulfil their demands to gain their daily livelihood.

....I am a patient of sugar (Diabetes Mellitus) and pressure (hypertension)...I want to go to the hospital, but I cannot go easily...the government cannot manage services for us. It is paradoxical to let people die from other diseases, to save people from the coronavirus. -FM16 
More or less, people were aware of the COVID-19. Majority of the public were reported as dutifully observing the lockdown. However, some had been violating the lockdown rules. People had great expectations from the police to help their community by taking strict actions against those who were violating rules.

Participants had opined that people who tried to break the rules of the lockdown must be punished since they could transfer disease to others. However, some participants considered it was not completely their fault as the efforts of the government were not enough to help the general public.

I have been working as a frontline health care worker in the nearby hospital. While going to the duty station by my motorcycle, the authorities are not allowing me to go, even if I show my identity card. Instead, they beat me with sticks and abused me verbally for breaking the lockdown rules. -IM19

Moreover, participants expressed concern for the people who had started walking on foot for many days to return to their home, and requested the government to take needful actions to let those hard-hit wayfarers reach home easily, despite the lockdown.

We are worried about those people (who are walking to reach their home)... (pause)...we can't imagine the journey they have started to walk from east to west. It would take months for them to reach their home. They are all daily wage workers and have no money to sustain. They should be supported. -FM20

Participants shared that the government had been trying but the designated quarantine facilities were insufficient and ineffective. They suggested to increase the number of quarantine facilities and convince people to stay in quarantine. They held the view that the health services provided in quarantine and isolation centres were not adequate.

...government is developing quarantine homes, but they are not appropriate. The protective measures have not been applied sufficiently. -FF18

Participants also expressed concern for the people who were stuck in lockdown and quarantined at the border areas.

It is troublesome for people who are stuck at the borders. What would happen to them if they remain in tents at the border? They are thousands in number. There is a high chance of transmission of the disease in the crowded quarantine facilities. -FF21

Moreover, the security personnel were worried about their health and requested the government to provide adequate PPE and let them be tested for the disease.
Theme 5: personal and societal consequences of COVID-19, social distancing and lockdown

Social discrimination and stigma

Participants reflected on their experiences of social discrimination and stigma in their communities. The healthcare workers were expelled from their rent houses; moreover, they were denied proper food and lodging in the hotels. The COVID-19 positive cases were disrespected in the community. The people who returned from abroad were shunned by the community people and those who were sent home from quarantine centres, after testing negative for PCR tests, were not permitted to enter their homes. The community people strongly opposed the local government's decision to make a quarantine centre in their village. The people who marched a long way to their home by foot were prohibited to walk near the streets and highways. In addition, participants reported that after a significant number of positive cases increased in a religious gathering, people started blaming religious groups for spreading the COVID-19.

The stigma was prevalent even among the local government bodies and police personnel. Trucks of vegetables and fruits were destroyed by the local administration after they came to know that those agricultural products came from the COVID-19-affected areas. Similarly, the police personnel manhandled the persons who came from abroad and were made to stay at home even if they tested negative for the PCR test.

The house owner has told me to leave the rented room as soon as possible, blaming me to be a major source of COVID-19 spread as I am a health worker. Where should I go all of a sudden? I feel regretful; I made a wrong decision by choosing this profession. $-\mathrm{IF} 24$

\section{Lack of social interaction}

Participants stayed at home due to social distancing and social isolation policy, except a few directly involved frontline workers such as healthcare workers and security personnel. They agreed that social interaction had decreased significantly and they were feeling socially isolated.

It's been so long that we have been staying at home. There's the same daily routine. We used to play carom and cards at the Chowk (junction). -FM26

However, a variation was found between the participants in rural and urban areas in terms of social interaction. The participants in urban areas said that they were strictly prohibiting any interaction with others. But people in villages or rural areas had different views. They said that they were meeting their neighbours while maintaining one metre distance, though the interaction had decreased in comparison to the pre-lockdown period. 
There are only houses and buildings with a high density of people living in this area. So we are prohibiting us from going anywhere. -FF11

\section{Economic loss}

Participants had varied experiences on the economic loss due to lockdown and social isolation policy. The daily wage workers were suffering the most who lamented that they did not have enough money to sustain their livelihood. They were worried about their family members as they were the only breadwinners in the family.

...what should I say sir (to the interviewer)...this lockdown has been a catastrophe for us. I used to earn money after working daily. I worked at the people's house. I did everything...from cleaning pots and pans to performing daily chores, and earned some money... (tears in eyes seen)... Now nobody is allowing even to walk anywhere. -IM28

Also, some participants brought up their concern of significant loss in their business due to the closure of the market. However, there were a few government officials who were not affected economically by the lockdown and social distancing, as the government had been paying them the monthly salary as usual.

\section{Changes in lifestyle}

The effect of lockdown and social distancing saw a significant variation in the lifestyles among people from the urban and rural areas. The people from the urban area were worried about their sluggish lifestyle since the start of lockdown.

We have become claustrophobic seeing the four walls of this home, daily. There is no place to go. No parks and open spaces nearby...people and media say that we should not leave our home...we have been doing even morning walk in a single room, going from one corner to another. -FF18

However, people in villages and rural areas had different experiences. They said that though they were not going anywhere they had still plenty of work to do in their fields and were busy.

This is the time for harvesting the wheat and prepare for planting the paddy. So, we are busy with it. Though we have been maintaining some distance among us, we haven't stopped our work. -FM32

On one hand, a few participants said that lockdown had created a good environment to be together with family members, and had enabled productive use of time, on the other hand, few participants were fed up of the prolonged and extended lockdown, and were worried about the change in their lifestyle.

\section{Psychological impact}

Experiences of anxiety, fear of being infected, and stress due to lack of interaction were shared by the participants.
They harbored the fear of spread of disease to village areas of Nepal, as many may die due to inadequacy of healthcare facilities. One of the participants shared about her children's escalating fear due to constant exposure to conversations of COVID-19 and its threat.

My son is a doctor. He is working in the COVID-19 hub hospital in the main city, where so many positive cases have been found. I fear that my son would be infected with it (COVID-19). Meanwhile, I can't say to him to leave the job and come home. I don't like speaking with anyone these days. Boredom and loneliness have been my friends. -FF6

The healthcare workers expressed fear of getting infected when providing treatment to COVID-19 positive and suspected cases, as they were not provided with adequate PPE. Moreover, they stated that they had not visited their families for months due to fear of transmitting the disease to the family members, which they admitted to making them feel lonely. Similar was the response from the security personnel who was fearful to work in the field away from home.

People whose family members were in foreign countries seemed to be more terrified and anxious. Moreover, people also claimed that the media played a negative role and the continuous information provided by it increased fear and anxiety among people.

\section{DISCUSSION}

This study explored the perceptions of the public towards COVID-19, and their experiences during the lockdown on lifestyle, mental health and social life. The study showed that participants possessed good knowledge about the origin, transmission, cause and prevention of COVID-19. They were aware that using masks and sanitisers, washing hands and maintaining social distance could help them prevent the disease, and they believed that awareness campaigns in rural areas were necessary. Mass media played a vital role in raising awareness among people; however, the need of checking the credibility of all information spread by social media was stressed upon by some participants. The finding of this research is in line with the study conducted in Bangladesh ${ }^{21}$ where most of the participants were aware of the COVID-19 pandemic, and their source of information was mass media. In the USA, ${ }^{16}$ most people exhibited good knowledge about the mode of transmission, causes and symptoms of the COVID-19. In this study, participants mentioned the potential risk factors of the disease, such as age and comorbidities, which were similar to the report published by the Center for Disease Control and Prevention. ${ }^{22}$ Similarly, the study conducted in Uganda ${ }^{23}$ reported that awareness and attitude played an important role in preventing the spread of COVID-19. Safe water, sanitation and hygiene are a must for defending against this virus. ${ }^{24}$ However, debates are still ongoing on the evidence of effectiveness of face masks as a prevention measure. ${ }^{25}$ One of the studies 
suggests that early public interest in face masks may be an independently important factor in controlling the COVID-19 epidemic on a population scale. One illustrative region is Hong Kong, where the public interest in face masks is among the highest due to the perception of masks preventing the disease transfer. ${ }^{26}$ The use of surgical masks in high risk and crowded areas can provide effective protection. ${ }^{25}$

Accurate information shared by media plays a role in shaping people's perceptions towards risk of contracting COVID-19; lack of accessibility to this information can serve as a barrier which in turn, can increase the probability of the infection. ${ }^{27}$ Similarly, a study conducted in India reported that most people have good knowledge and right practice towards COVID-19, but gaps persist in the right perception of myths and misconceptions. It suggests providing educational programmes to rectify misconceptions about COVID-19 and improving the knowledge, perception and practices. ${ }^{14}$ Moreover, there was good knowledge on the situation of COVID-19 but poor perceived knowledge on preventive measures. ${ }^{28}$

A study conducted in Nepal revealed that the knowledge of people about COVID-19 was high, but there was a gap in knowledge on social distancing and quarantine. There was a positive perception towards universal safety measures of COVID-19, but negative perceptions also existed such as: COVID-19 attacked only older people; and coughing into the elbow was not good practice to prevent the spread of the virus. ${ }^{15}$

Participants also believed in: survival of the virus in hot temperatures, meat and egg consumption causing the disease, and the potential role of turmeric, onion, tea and alcohol in preventing it. Similar to it, a study in Afghanistan showed that $89 \%$ of the participants believed that during the outbreak, eating well-cooked and safely handled meat is safe. ${ }^{29}$ Similarly, a study conducted in India showed that social media played a major role in spreading awareness among the public, however, the spread of fake news was also reported, highlighting racism issues during the epidemic which created panic and negative influence on people's mental health and psychological well-being. ${ }^{3031}$ Similarly, one study revealed a misconception that exposure to the sun or temperature more than $25^{\circ} \mathrm{C}$ prevents the disease which then cannot spread further in hot and humid climates. Other studies also reported misconceptions around the disease such as: people cannot completely recover from the COVID-19 once they suffer; drinking alcohol prevents the disease; coronavirus is transmitted through mosquito bites; hand dryers are enough for killing SARS-CoV-2; antibiotics are effective for the treatment of COVID-19; garlic and honey help in curing the disease; the acid in our stomach kills the virus if we drink enough water; clapping hands create vibrations that destroy the virus; religious chants can kill the virus $;{ }^{32}{ }^{33}$ and low-income countries are more immune to COVID-19. ${ }^{34}$ Also in a study from Australia, $42 \%$ of participants thought that being unable to hold your breath for 10 seconds without coughing was an indication of having the virus. Among the participants, $83 \%$ held at least one COVID-19-related misconception with the most frequent being that the virus was created in a laboratory $(36 \%){ }^{35}$

This research has also highlighted the expectations of the people and challenges of the government to control the COVID-19 pandemic in Nepal. Inadequate PPE for health workforce, health system mismanagement, lack of sufficient and effective quarantine centres, and the violation of lockdown were some of the challenges during this pandemic situation that were put forward by the participants. Similar to this study, the lack of protective equipment and transportation were the difficulties experienced by rural residents in China during the epidemic. ${ }^{36}$ A study conducted in Nepal showed that a shortage of test kit and medical supplies including PPE, poor coordination among different tiers of government and poor reporting were the major challenges in containing COVID-19. The high population density in the urban areas of South Asia makes it difficult for people to maintain social distancing and proper personal hygiene.$^{37} \mathrm{PPE}$ is essential to reduce viral transmission and prevent the spread of the disease among the healthcare workers and patients, ${ }^{38} 39$ but shortage, inappropriate use and misuse of PPE were identified as the major problems in the $\mathrm{UK},{ }^{38}$ and shortage of PPE in high-demand areas like triage and isolation wards of India has resulted in severe problems. ${ }^{39}$ A study conducted in Italy revealed that only 13\% of physicians reported having access to PPE every time they needed them. ${ }^{40}$ In Thailand, contact tracing is most effective but mass screening cannot be afforded by the government. ${ }^{41}$ Similarly, a study conducted in Taiwan revealed that testing only symptomatic cases can miss many asymptomatic infections and render contact tracing less effective. ${ }^{42}$

Tackling the violation of lockdown rules is one of the biggest challenges for the government. A study has shown that strict mitigation measures, if implemented in a timely manner, greatly outperform lengthy quarantines and lockdowns. ${ }^{43}$ Social distancing is regarded as the most effective measure for mitigation of the disease $\mathrm{e}^{44}$; additionally, early lockdown reduces the effects of the disease. ${ }^{45}$ The experience of China suggested that social distancing is a deliberate effort to slow down the spread of infectious or contagious diseases. Keeping that in mind, most of the countries focused on social distancing and lockdown systems to prevent the spread of the disease. ${ }^{46}$ Similarly, participants from a study believed that quarantine, social distancing and the use of face masks can actually break the chain of COVID-19 spread. ${ }^{47}$ In Pakistan, the forced lockdown was not feasible, so it changed into a partial lockdown first and then into a smart lockdown. ${ }^{48}$ Therefore, lockdown is a hard choice and challenging in order to maintain essential services. ${ }^{49}$

According to a study conducted in Nepal, a long and strict lockdown had negative effects on many health aspects of people and the community: many women are facing barrier in accessing maternal health services; data have shown an increase in suicide attempts; children 
and students felt stressed due to uncertainty about the future. ${ }^{12}$ Quarantine is effective to control the COVID$19,{ }^{50}$ but its effective management is a challenge for the government. However, increase in abusive behavior highlights the negative aspects of isolation and quarantine at home. $^{12}$

The impact of the pandemic and lockdown on public is enormous: people opined that the disease and its consequences reduced social interaction, exacerbated the economic crisis, increased psychological effects (fear, anxiety and depression) and also changed the lifestyle of the people in many ways. In rural areas, however COVID-19 wasn't reported to bring considerable changes in lifestyle. Interestingly, for some participants, lockdown had some positive impacts as well as it helped them to have quality time with their family members and helped them feel refreshed.

This study showed that COVID-19 has led to high degree of social stigma and discrimination, especially towards health workers, their family members, people coming from abroad, and people living in quarantine. According to UNICEF, COVID-19 is a new disease with many unknowns; these unknown factors have led to anxiety among the public, ${ }^{51}$ which has in turn fueled stigma and discrimination. ${ }^{52}$ Other studies also showed that healthcare workers, people released from quarantine, people returning from travel, and people with the disease and their families also faced social stigma. ${ }^{53}$ A study revealed that healthcare providers working in hospitals and laboratories are discriminated against and are facing difficulties for food and shelters, with the neighbours refusing to interact with them while showing their displeasure.$^{54}$ Similar to this study, in Nepal also, health workers were expelled from their rooms and were faced with the difficulty of getting food in the hotel. This kind of discrimination makes people socially isolated, and can leave them angry and depressed. ${ }^{53}$ A qualitative study was conducted in Lorestan University of Medical Sciences, Iran to explore the perception of nurses on taking care of patients with COVID-19, which revealed that nurses experienced many challenges such as physical fatigue, stress, anxiety, feeling of insufficiency, and being enclosed in protective equipment during caretaking; all these led to a decrease in the quality of patients' care..$^{55}$

Social distancing and social isolation during COVID-19 have affected most people in a negative way. It has reduced social interactions, changed lifestyle, led to economic loss and resulted in psychological crises. Social isolation increases loneliness which is a risk factor for various psychological conditions. ${ }^{56}$ A study conducted in the UK also showed that social distancing and isolation had negative impacts on the mental health and well-being of people. It also affects employment, economy, individual's worthiness, and daily routines of people leading to psychological and emotional loss. ${ }^{57}$

\section{Strengths and limitations}

The major strength of this study is the use of a maximum variation sample method which enabled the representation of participants from diverse backgrounds in terms of gender, profession, education, geography and social status. A large number of participants were interviewed in a short period of time abiding preventive measures and safety guidelines. Furthermore, the use of the phenomenological approach was instrumental in translating messages from people's lived experiences during this pandemic situation in this research. This study has a wide geographical coverage of study sites covering three out of seven provinces including the capital city of Nepal. The use of qualitative methods may render the findings not generalisable, however, the evidence generated is useful to design quantitative research to understand the burden of issues and the impact of the COVID-19 on the population at large. Other limitations include the possibility of having interviews and data collection being influenced by the experiences of the research team regarding COVID-19. Due to different stages of lockdown and disease outbreak in different parts of the country, people were hesitant to participate in FGDs and somewhere they were discouraged by the authorities. To address this issue, government-set rules and regulations for the public gathering were followed, that is, maintenance of 1-metre distance, use of masks and sanitisers; and they were ensured of safety and free will to withdraw any time. Similarly, since the children and elderly population were excluded from the study due to the possibility of an increased risk of COVID-19, their views and experiences could not be understood. Moreover, this was a short-term study conducted over a period of 2 weeks. The long-term experience of the participants may provide a better understanding of people's experiences during the pandemic.

\section{CONCLUSIONS}

People believed that the use of masks and sanitisers, frequent hand washing, maintaining social distance and manageable lockdown help in preventing the disease. Similarly, social distancing, isolation and economic loss during lockdown increase the risk of psychological problems, implying the need for professional counselling. High expectations from people, inadequate supply of PPE, violation of the lockdown, unprepared health system, poor management of quarantines and the rumours created by social media are challenges faced by the government during this pandemic. There is a need for improvement in the effective management of the COVID-19.

The findings from this study can contribute in planning policies and generating guidelines that can improve the physical as well as psychological health of the public, including the healthcare providers, the security personnel as well as the frontline care providers. Further research may help reduce the myths and misconceptions. Based on 
the local status quo of the pandemic, local governments may be in a better place to administer and implement local social distancing policies. The three tiers of government need to work based on the principle of coordination, cooperation and coexistence to strengthen its health system. There is a need to identify ways to strengthen surveillance, contact tracing, quarantine and isolation centres management. Also, engaging with public through mass awareness campaigns and establishing strong and coordinated mitigating measures in place is a must.

\section{Author affiliations}

${ }^{1}$ Bayalpata Hospital, Nyaya Health Nepal, Achham, Nepal

${ }^{2}$ Department of Health Services, Government of Nepal Ministry of Health and Population, Kathmandu, Nepal

${ }^{3}$ Central Department of Public Health, Tribhuvan University Institute of Medicine, Kathmandu, Nepal

${ }^{4}$ College of Dental Surgery, B.P. Koirala Institute of Health Sciences, Dharan, Nepal ${ }^{5}$ Nepal Health Sector Support Programme (NHSSP)/DFID, Government of Nepal Ministry of Health and Population, Kathmandu, Nepal

${ }^{6}$ Department of Research, Golden Community, Lalitpur, Nepal

\section{Twitter Navin Bhatt @nnavinbhatt}

Acknowledgements We acknowledge the support received from Mr Tribhuwan Bhatta and Ms Pooja Uprety during data collection. The authors thank the participants for their participation in the study.

Contributors NB, BB, SG and SSB conceptualised and designed the study. NB, BB, $S G, S D$ and $A R J$ contributed to the literature review. NB, SD and ARJ contributed to data collection. NB, BB, SG and SSB contributed to data analysis. NB, BB, SG, BN and SSB contributed to data interpretation. NB, BB and SG wrote the first draft and received input from SD, ARJ, BN and SBB during revision. All authors performed draft editing and final draft preparation. All authors read and approved the final manuscript.

Funding The authors have not declared a specific grant for this research from any funding agency in the public, commercial or not-for-profit sectors.

Competing interests None declared.

Patient consent for publication Not required.

Ethics approval Ethical approval was obtained from the Ethical Review Board of the Nepal Health Research Council prior to the conduction of the study (Ref. No. 2124). Informed consent was taken with all the participants before the interview/discussion took place. The participants were assured of their privacy and confidentiality, and that the data collected would only be accessible to the research team. Participants were informed of their right to refuse to participate in the study or withdraw from the discussion at any time. At the end of each focus group discussion and in-depth interview, participants as well as other interested people who were available at the data collection hubs were given pamphlets containing essential and evidence-based information on COVID-19 supplemented with ways of protecting their mental and psychological health.

Provenance and peer review Not commissioned; externally peer reviewed.

Data availability statement All data relevant to the study are included in the article or uploaded as supplemental information.

Supplemental material This content has been supplied by the author(s). It has not been vetted by BMJ Publishing Group Limited (BMJ) and may not have been peer-reviewed. Any opinions or recommendations discussed are solely those of the author(s) and are not endorsed by BMJ. BMJ disclaims all liability and responsibility arising from any reliance placed on the content. Where the content includes any translated material, BMJ does not warrant the accuracy and reliability of the translations (including but not limited to local regulations, clinical guidelines, terminology, drug names and drug dosages), and is not responsible for any error and/or omissions arising from translation and adaptation or otherwise.

Open access This is an open access article distributed in accordance with the Creative Commons Attribution Non Commercial (CC BY-NC 4.0) license, which permits others to distribute, remix, adapt, build upon this work non-commercially, and license their derivative works on different terms, provided the original work is properly cited, appropriate credit is given, any changes made indicated, and the use is non-commercial. See: http://creativecommons.org/licenses/by-nc/4.0/.

\section{ORCID iDs}

Navin Bhatt http://orcid.org/0000-0002-2260-373X

Bandana Bhatt http://orcid.org/0000-0002-1202-606X

Shyam Sundar Budhathoki http://orcid.org/0000-0002-8614-1087

\section{REFERENCES}

1 World Health Organization. Coronavirus, 2020. Available: https:// www.who.int/health-topics/coronavirus\#tab=tab_1 [Accessed 23 Jul 2020].

2 Yuen K-S, Ye Z-W, Fung S-Y, et al. SARS-CoV-2 and COVID-19: the most important research questions. Cell Biosci 2020;10:1-5.

3 Cucinotta D, Vanelli M. WHO declares COVID-19 a pandemic. Acta Biomed 2020;91:157-60.

4 Ministry of Health and Population. Latest update of Nepal: COVID-19, 2020. Available: https://covid19.mohp.gov.np/\#/ [Accessed 7 Nov 2020].

5 Bastola A, Sah R, Rodriguez-Morales AJ, et al. The first 2019 novel coronavirus case in Nepal. Lancet Infect Dis 2020;20:279-80.

6 Chalise HN, Pathak KP. Situation of COVID-19 pandemic in South Asia. J Heal Allied Sci 2020;10:11-14.

7 Kaplan J, Frias L, McFall-Johnsen M. Our ongoing list of how countries are reopening, and which ones remain under lockdown, 2020. Available: https://www.businessinsider.com/countries-onlockdown-coronavirus-italy-2020-3 [Accessed 20 Jul 2020].

8 Piryani RM, Piryani S, Shah JN. Nepal's response to contain COVID-19 infection. J Nepal Health Res Counc 2020;18:128-34.

9 Government of Nepal-Ministory of Health and Population. Health sector emergency response plan COVID-19, 2020. Available: https:// publichealthupdate.com/health-sector-emergency-response-planmohp-nepal/

$10 \mathrm{Nepal}$ Government. Address to the nation by right Honorable prime minister KP Sharma Oli on control and prevention of coronavirus, 2020. Available: https://mofa.gov.np/address-to-the-nation-by-righthonorable-prime-minister-kp-sharma-oli-on-control-and-preventionof-coronavirus/ [Accessed 20 Jul 2020].

11 Wang C, Pan R, Wan X, et al. Immediate psychological responses and associated factors during the initial stage of the 2019 coronavirus disease (COVID-19) epidemic among the general population in China. Int J Environ Res Public Health 2020;17:1729.

12 Mahato P, Tamang P, Simkhada P, et al. Effects of COVID-19 during lockdown in Nepal. Eur J Med Sci. 2020;2:1-5. doi:10.46405/ejms. v2i2.91

13 Khanal P, Devkota N, Dahal M, et al. Mental health impacts among health workers during COVID-19 in a low resource setting: a crosssectional survey from Nepal. Global Health 2020;16:89.

14 Narayana G, Pradeepkumar B, Ramaiah JD, et al. Knowledge, perception, and practices towards COVID-19 pandemic among general public of India: a cross-sectional online survey. Curr Med Res Pract 2020;10:153-9.

15 Singh DR, Sunuwar DR, Karki K, et al. Knowledge and perception towards universal safety precautions during early phase of the COVID-19 outbreak in Nepal. J Community Health 2020;45:1116-22.

16 Geldsetzer P. Knowledge and perceptions of COVID-19 among the general public in the United States and the United Kingdom: a crosssectional online survey. Ann Intern Med 2020;173:157-60.

17 Ives J, Greenfield S, Parry JM, et al. Healthcare workers' attitudes to working during pandemic influenza: a qualitative study. BMC Public Health 2009;9:1-13.

18 Gohel KH, Patel PB, Shah PM, et al. Knowledge and perceptions about COVID-19 among the medical and allied health science students in India: an online cross-sectional survey. Clin Epidemiol Glob Health 2020. doi:10.1016/j.cegh.2020.07.008. [Epub ahead of print: 1208 2020].

19 Brinkmann S, Kvale S. Interviews: learning the craft of qualitative research interviewing. 2nd Ed. Sage, 2009: 354p.

20 Morrow R, Rodriguez A, King N. Colaizzi's descriptive phenomenological method. Psychologist 2015;28:643-4.

21 Farhana KM, Mannan KA. Knowledge and perception towards novel coronavirus (COVID-19) in Bangladesh. Int Res J Bus Soc Sci 2020;6:76-9.

22 Center for Disease Control and Prevention. Assessing risk factors for severe COVID-19 illness, 2020. Available: https://www.cdc. gov/coronavirus/2019-ncov/covid-data/investigations-discovery/ assessing-risk-factors.html [Accessed 20 Mar 2020]. 
23 Ssebuufu R, Sikakulya FK, Binezero SM. Awareness knowledge attitude and practice towards measures for prevention of the spread of COVID-19 in the Ugandans: a nationwide online cross-sectional survey. Medrxiv 2020:1-28 http://medrxiv.org/cgi/content/short/2020. 05.05.20092247

24 World Health Organization. Water, sanitation, hygiene and waste management for the COVID-19 virus, 2020. Available: https://apps. who.int/iris/bitstream/handle/10665/331846/WHO-2019-nCoV-IPC_ WASH-2020.3-eng.pdf [Accessed 20 Jul 2020].

25 Feng S, Shen C, Xia N, et al. Rational use of face masks in the COVID-19 pandemic. Lancet Respir Med 2020;8:434-6.

26 Wong SH, Teoh JYC, Leung C-H, et al. COVID-19 and public interest in face mask use. Am J Respir Crit Care Med 2020;202:453-5.

27 Zegarra A, Chino B, Ames R. Knowledge, perception and attitudes in regard to COVID-19 pandemic in Peruvian population. Salud Ment y Epidemiol en el Sur del Perú 2020:1-28. doi:10.31234/osf. io/kr9ya

28 Jose R, Narendran M, Bindu A, et al. Public perception and preparedness for the pandemic COVID 19: a health belief model approach. Clin Epidemiol Glob Health 2020:1-6. doi:10.1016/j. cegh.2020.06.009

29 Raghavan V, Jabbarkhail DN, Ahmady A. Health worker's perception survey on COVID 19: Knowledge, Perception, and Practice Survey of health workers in Eight Provinces of Afghanistan, 2020. Available: https://reliefweb.int/sites/reliefweb.int/files/resources/Health Worker_s_Perception_Survey_FInal_20052020.pdf [Accessed 20 Mar 2020].

30 Kadam AB, Atre SR. Social media panic and COVID-19 in India. $J$ Travel Med 2020;27:taaa057. doi:10.1093/jtm/taaa057

31 Ahmad AR, Murad HR. The impact of social media on panic during the COVID-19 pandemic in Iraqi Kurdistan: online questionnaire study. J Med Internet Res 2020;22:e19556.

32 Menon GI. COVID-19: Busting some myths. health and medicine, 2020. Available: https://indiabioscience.org/columns/indian-scenario/ covid-19-busting-some-myths [Accessed 20 Mar 2020].

33 Dutta S, Acharya S, Shukla S, et al. COVID-19 Pandemic- revisiting the myths. SSRG-IJMS 2020;7:7-10.

34 Roy S. Low-Income countries are more immune to COVID-19: a misconception. Indian J Med Sci 2020;72:5-7.

35 Thomas R, Greenwood H, Michaleff ZA, et al. Examining Australian's beliefs, misconceptions, and sources of information for COVID-19: A national online survey 2020.

36 Lihua M, Ma L, Liu H, et al. Knowledge, Beliefs/Attitudes, and practices of rural residents in the prevention and control of COVID-19: an online questionnaire survey. Am J Trop Med Hyg 2020;103:2357-67. doi:10.4269/ajtmh.20-0314

37 Asim M, Sathian B, van Teijlingen E, et al. COVID-19 pandemic: public health implications in Nepal. Nepal J Epidemiol 2020;10:817-20.

38 Cook TM. Personal protective equipment during the coronavirus disease (COVID) 2019 pandemic - a narrative review. Anaesthesia 2020;75:920-7.

39 Bhattacharya S, Hossain MM, Singh A. Addressing the shortage of personal protective equipment during the COVID-19 pandemic in India-A public health perspective. AIMS Public Health 2020;7:223-7.

40 Savoia E, Argentini G, Gori D, et al. Factors associated with access and use of PPE during COVID-19: a cross-sectional study of Italian physicians. PLoS One 2020;15:e0239024.
41 Chaitrong W. Mass-testing not that effective in battle against contagion. The nation Thailand, 2020. Available: https://www. nationthailand.com/news/30385921 [Accessed 20 Sep 2020].

42 Wang CJ, Ng CY, Brook RH. Response to COVID-19 in Taiwan: big data analytics, new technology, and proactive testing. JAMA 2020;323:1341-2.

43 Mayorga AL, Samartino CG, Flores G, et al. COVID-19 lockdown : if, when and how. Medrix 2020:1-12.

44 Singh R, Adhikari R. Age-Structured impact of social distancing on the COVID-19 epidemic in India. Quant Biol 2020:1-9 http://arxiv.org/ abs/2003.12055

45 Zhang Y, Jiang B, Yuan J, et al. The impact of social distancing and EpiCenter lockdown on the COVID-19 epidemic in mainland China: a data-driven SEIQR model study. medRxiv 2020:1-14.

46 Musinguzi G, Asamoah BO. The science of social distancing and total lock down: does it work? whom does it benefit? Electron J Gen Med 2020;17:em230-9.

47 Vadivu TS, Annamuthu P. An awareness and perception of COVID -19 among general public - a cross sectional analysis. Int $J$ Mod Trends Sci Technol 2020;6:49-53.

48 Rukh L, Nafees M, Khan F. Evaluation of Forced-Lockdown, partial Lockdown and Smart-Lockdown against COVID- 19 hazard and related problems: an example from Pakistan, 2020. Available: https://www.researchgate.net/publication/340940868_Evaluation_ of_Forced-Lockdown_Partial_Lockdown_and_Smart-Lockdown_ against_COVID-19 Hazard_and_Related_Problems_An_Example from_Pakistan [Accessed 12 Jun 2020].

49 Sarwal R, Sarwal T. Mitigating COVID-19 With Lockdowns : A Possible Exit Strategy, 2020. Available: https://papers.ssrn.com/sol3/ papers.cfm?abstract_id=3563538 [Accessed 12 Jun 2020].

50 Nussbaumer-Streit B, Mayr V, Dobrescu Al, et al. Quarantine alone or in combination with other public health measures to control COVID-19: a rapid review. Cochrane Database Syst Rev 2020;4:CD013574.

51 The United Nations Children's Fund. Social stigma associated with the coronavirus disease (COVID-19), 2020. Available: https:// www.unicef.org/documents/social-stigma-associated-coronavirusdisease-covid-19 [Accessed 12 Jun 2020].

52 Gupta TK. Social stigma during COVID-19 pandemic, 2020. Available: https://thehimalayantimes.com/opinion/social-stigmaduring-covid-19-pandemic/ [Accessed 12 Jun 2020].

53 MAYO CLINIC. COVID-19 (coronavirus) stigma: what it is and how to reduce it, 2020. Available: https://www.mayoclinic.org/diseasesconditions/coronavirus/in-depth/coronavirus-stigma/art-20484278 [Accessed 12 Jun 2020].

54 Singh R, Subedi M. COVID-19 and stigma: social discrimination towards frontline healthcare providers and COVID-19 recovered patients in Nepal. Asian J Psychiatr 2020;53:102222.

55 Galehdar N, Toulabi T, Kamran A, et al. Exploring nurses' perception of taking care of patients with coronavirus disease (COVID-19): A qualitative study. Nurs Open 2020;7:1-9.

56 Douglas M, Katikireddi SV, Taulbut M, et al. Mitigating the wider health effects of covid-19 pandemic response. $B M$ 2020;369:m1557

57 Williams SN, Armitage CJ, Tampe T, et al. Public perceptions and experiences of social distancing and social isolation during the COVID-19 pandemic: a UK-based focus group study. BMJ Open 2020;10:e039334. 